\title{
LA IMAGEN DE PARTIDO DEL PARTIDO POPULAR Y EL PARTIDO SOCIALISTA OBRERO ESPAÑOL EN ES- PAÑA: 1996 AL 2015
}

THE PARTY IMAGE OF THE POPULAR PARTY AND THE SPANISH SOCIALIST WORKERS PARTY IN SPAIN: 1996 TO 2015

Antonio Alaminos

Universidad de Alicante alaminos@ua.es

\section{Resumen}

La "imagen del partido" refiere a los atributos y cualidades que los ciudadanos les otorgan a estos. Dichas cualidades pueden ser ideológicas o referirse a otros aspectos significativos propios de toda imagen pública. Un logo de partido o sus siglas son en definitiva una "marca" con un determinado nivel de reputación, confianza o fiabilidad que le diferencia de los demás partidos. En esta investigación se estudia las imágenes del Partido Popular y del Partido Socialista Obrero Español a partir de la capacidad que se les concede para gestionar diferentes políticas. En definitiva, qué dimensiones de lo social, lo económico o lo político se considera que le son más afines y para los que se les supone más competentes. A partir de cinco encuestas preelectorales de elecciones generales efectuadas por el CIS, en 1996, 2000, 2008, 2011 y 2015 se analiza el perfil del PP y del PSOE. La hipótesis general, establecida a nivel internacional para los partidos mayoritarios con experiencia de gobierno, plantea la convergencia temática, así como una tendencia a la indiferenciación en sus perfiles políticos. En definitiva, una debilidad de "imagen de partido" en la opinión pública. Para el caso español, esta hipótesis se confirma, mostrando una indiferenciación en los temas políticos considerados en la imagen de partido del PP y del PSOE.

Palabras clave: Imagen de partido, PP, PSOE, líneas de conflicto electoral 


\section{Abstract}

The "image of the political party" refers to the attributes and qualities that citizens give them. These qualities can be ideological or refer to other significant aspects of any public image. A political party logo or its acronym is a "brand" with a certain level of reputation, trust or reliability that differentiates it from other political parties. This research studies the images of the Popular Party and the Spanish Socialist Workers Party based on the capacity granted to them to manage different policies. In short, what dimensions of the social, economic or political are more related with them, and for those who are supposed to be more competent. From five pre-election surveys of general elections carried out by the CIS, in 1996, 2000, 2008, 2011 and 2015 the profile of the PP and the PSOE is analysed. The general hypothesis, established at the international level for the majority parties with government experience, raises the thematic convergence, as well as a tendency towards undifferentiation in their political profiles. In short, a weakness of the "party image" in public opinion. For the Spanish case, this hypothesis is confirmed, showing a general tendency to undifferentiation in the political issues considered in the party image of the PP and the PSOE.

Keywords: Image of political party, PP, PSOE, lines of electoral conflict

\section{INTRODUCCIÓN}

Un aspecto especialmente significativo de los partidos políticos es su imagen pública. Con mayor efecto, si cabe, en la sociedad de la información. Una imagen que trasciende lo exclusivamente ideológico (o el carisma de sus líderes) y que incorpora dimensiones de carácter funcional como es la competencia de gestión, su interés o afinidad con determinados problemas y cuestiones sociales. En definitiva, las etiquetas y atributos de interés colectivo que se adjudican a los diferentes partidos en su oferta como alternativas políticas (y por lo tanto teóricamente con una oferta diferenciada en la priorización de los temas relevantes, así como de su posible tratamiento político). Esta característica de los partidos políticos es propia de cualquier objeto político, incluyendo la de los líderes políticos.

Los dos se convierten en potenciales motivaciones de voto, según las cuales para algunos electores es atrayente la imagen del líder (Adolfo Suarez o Felipe González, por ejemplo) con sus propios atributos, mientras que para otros lo es la imagen del partido (su trayectoria política, los temas cuya defensa o promoción considera propios, logos o simbologías). En determinadas ocasiones, como las elecciones generales de 1996 y 2000 en España, la imagen del líder (Aznar) fue percibida mucho más moderada y centrista que la del partido que lideraba 
(Partido Popular), permitiendo efectuar una doble articulación ideológica que cubrió todo el espectro desde el centro a la extrema derecha. La imagen del líder llegaba a electorados centrados que el partido político (por su fuerte imagen conservadora) era incapaz de alcanzar. Los dos son piezas de un mismo motor político que pueden trabajar de forma diferenciada, ya sea coordinada o contradictoriamente. En ese sentido, si bien el liderazgo tiene un efecto definido sobre los electorados (Cohen, 2015), también la imagen del partido es un elemento de largo plazo que permanece activo en varias convocatorias electorales.

La imagen de partido mantiene una relación con la imagen del líder de dicho partido, en la medida que este último puede condicionar e incluso desplazar en el largo plazo la imagen del primero. Los dos (partido y líder) pueden considerarse “objetos políticos" (Almond y Verba, 1965; Easton, 1975) diferenciados, que forman parte de la cultura política de un país. Almond y Verba definían cultura política como "una distribución particular de pautas de orientación hacia objetos políticos entre los miembros de una nación" (Almond y Verba, 1965:13). En dicha línea argumental, Easton definía "apoyo político" como "una actitud por la que una persona se orienta a si mismo hacia un objeto de forma favorable o desfavorable, positiva o negativa" (Easton, 1975:436). Almond y Verba (1965) siguiendo a Parsons y Shils (1951), distinguían entre tres tipos de actitudes según su base de orientación cognitiva, afectiva o evaluativa. Así, la orientación cognitiva parte de los conocimientos y creencias sobre el sistema político, los políticos y demás elementos. En la formación de esta orientación influyen de modo especial los medios de comunicación, así como la experiencia directa del individuo a partir de actuaciones o contactos con los partidos. Las orientaciones afectivas son sentimientos hacia el sistema político, sus roles, personas y actuaciones. Con un peso elevado de la socialización en grupos primarios o las afinidades personales de naturaleza subjetiva. Por último, las orientaciones evaluativas vienen dadas por juicios y opiniones sobre los objetos políticos en los que generalmente se entremezclan tanto valores como la información recibida.

En el estudio de las imágenes de los partidos considerados como "objetos políticos" se entremezclan las tres orientaciones de forma indiferenciada. Para poder distinguir operativamente el efecto de cada una de las orientaciones sobre la imagen de partido es preciso un diseño específico que considere los aspectos racionales y comunicacionales de la política (Bouza, 1998, 2004; González y Bouza, 2009; Chavero et al., 2013). En el caso que nos ocupa, esto no es posible al emplearse datos de fuentes secundarias, con información procedente de estudios de opinión pública ya efectuados. En ese sentido, solamente cabe estudiar los efectos tal y como se expresan en las imágenes de partido, sin caber la posibilidad de diferenciar entre el peso de las orientaciones que las definen. 
La imagen de partido forma parte de los "objetos políticos" mediante los que puede expresarse el apoyo o el rechazo político. Entre los primeros estudios de la imagen de partido y sus efectos se encuentran los de Trilling (1976) y Wattenberg (1986). Trilling tras analizar el periodo entre 1952 a 1972, concluye que los impactos coyunturales (por ejemplo, la guerra de Vietnam) tenían un efecto muy limitado sobre la imagen de los partidos políticos en los Estados Unidos. Las imágenes de los partidos eran, para dicho estudio en concreto, resilientes a impactos coyunturales.

Wattenberg, investigando el periodo 1952 a 1984 llega a la conclusión de que se aprecia un debilitamiento de las políticas económicas o de bienestar como rasgos significativos para identificar de forma particular la imagen del Partido Republicano y del Partido Demócrata en los Estados Unidos de América. En la conclusión de este autor, se había producido una dinámica de convergencia entre las posiciones y actuaciones políticas de los dos partidos de tal modo que alcanzaba un punto de equilibrio o neutralidad en las imágenes de los dos partidos. En otras palabras, que dichos temas no eran distintivos de ninguno de los dos partidos, diluyendo dichas líneas de conflicto del espacio temático que define la competencia electoral.

Brewer (2009), tras analizar en Estados Unidos de América las imágenes de partido en relación con diversas "cleavages" (raza, género, religión, clase) llega a la conclusión de que sí existe diferencias significativas en los perfiles de los dos partidos mayoritarios. Las diferencias se atenúan para población general, pero se conservan vivas y activas al comparar posiciones estructurales en la sociedad. Este autor afirma como las imágenes se forman a lo largo de años, décadas, y sirven como elemento para que los electores interpreten lo que proponen los líderes políticos y sus partidos. Es a partir de una imagen de partido sólidamente establecida que los políticos puedan efectuar discursos "irónicos" en la medida que lo planteado sea ajeno a su imagen. En ese sentido, para el caso español que nos ocupa, cabe destacar que la ironía no es un recurso retorico frecuente en los discursos políticos. De adoptar el empleo de efectos retóricos ambiguos (como la ironía, por ejemplo) como un indicador de distancia entre las imágenes de los partidos, se confirma la escasa presencia de esta. Ciertamente, solo desde una imagen de partido sólida y bien definida es posible la ironía, parafraseando las propuestas políticas de otros partidos.

La robustez y solidez de las imágenes de partidos, ofreciendo perfiles distintivos nítidos respecto a otros partidos, es compatible con el cambio en el trascurso del tiempo. Así, Brewer (2009) o Sanders (1988) muestran como las imágenes de los partidos cambian en el tiempo. Así, su imagen se ve modificada paulatinamente dependiendo de sus actuaciones políticas. Es este hecho dinámico el que permite el efecto de convergencia de imágenes de diferentes parti- 
dos, especialmente sobre el impulso de las orientaciones cognitivas (realizan las mismas políticas) y en menor grado de las evaluativas. Más robustas son las orientaciones afectivas, que se encuentran en la base de la noción de voto militante o fiel, y con ello con un grado elevado de insensibilidad a la coincidencia de políticas en la definición de su imagen de partido.

Una de las cuestiones centrales en la actualidad es el papel de los partidos políticos, su imagen de alternancia o de diversificación en las políticas. Varias de las crisis políticas que han vivido las democracias europeas en el siglo XXI han estado relacionadas con la coincidencia en la gestión de gobierno que practican los partidos políticos en competencia. Con frecuencia, llegando a establecer un doble discurso en el que el programa electoral entra en flagrante contradicción con la práctica de gobierno. Un ejemplo reciente en España de esto lo encontramos en el programa que el Partido Popular proponía en las elecciones generales de 2011, muy alejado de lo que fueron sus decisiones como gobierno.

Ya sea desde la práctica de gobierno o desde las propuestas políticas, la realidad ofrece una convergencia de los partidos mayoritarios en sus actuaciones políticas llegando a no diferenciarse y diluyendo su imagen de partido. Precisamente, las imágenes de partidos más definidas en la actualidad corresponden con partidos extremistas cuyos perfiles políticos se caracterizan por sus aristas respecto a las políticas convencionales. Dado que los partidos políticos son percibidos por la sociedad en base a su posición respecto con diferentes dimensiones económicas, sociales, ideológicas, los temas que caracterizan la imagen de partido en la opinión publica determina indirectamente las líneas de conflicto (alternativa política) que pueden establecerse entre ellos. En especial cuando existen experiencias de gobierno con los partidos centrales del sistema, de tal modo que la coincidencia entre ellos reduce la capacidad de ofrecer alternativas reales a los electores. Por ejemplo, la coincidencia en las políticas económicas del Partido Socialista Obrero Español y el Partido Popular es máxima dado que utilizan modelos de interpretación macroeconómica similares. Si bien la lógica indica que la coincidencia se maximiza en periodos de crisis, los partidos tendrían margen de diferenciación en periodos de expansión, donde la redistribución puede entrar como elemento diferenciador. Sin embargo, esta oportunidad ha sido utilizada siempre. Un ejemplo es el caso del gobierno del Partido Socialista Obrero Español desde 2004, que optó por redistribuciones económicas generalistas ("cheque bebe" sin criterio de renta, devolución de impuestos, etc.) mientras perfilaba su imagen en la potenciación de leyes referidas al género. La pérdida de nitidez de las imágenes de partido en España ha sido en parte consecuencia de la eliminación de los perfiles distintivos de la socialdemocracia, juntamente con una atenuación del grado de conservadurismo social del Partido Popular (Alaminos y Penalva, 2013). Esta dinámica de confusión de perfiles y supresión de líneas de conflicto en los programas políticos entre 
partidos ha sido generalizada en muchas de las democracias europeas, en parte como consecuencia de la coordinación de políticas económicas y sociales organizada desde las instituciones europeas, (caso del Banco Central Europeo). En ese sentido, la atenuación de los perfiles económicos y sociales de las imágenes de partido son tanto el resultado de una visión única de las actuaciones económicas posibles, como de las políticas acordadas en el ámbito supranacional. Precisamente, los partidos con una imagen más definida (extrema derecha o extrema izquierda) están en colisión constante con las políticas europeas. Y viceversa. Los partidos políticos normalizados tienden, dentro del espacio europeo, a la puesta en común de políticas.

Entre las consecuencias de la debilitación de los perfiles propios que definen la imagen de partido de los diferentes partidos políticos del sistema de partidos, Wattenberg (2000) propone que se produce una progresiva irrelevancia de los partidos políticos para gran parte de los electorados. Una irrelevancia, entre otras causas, consecuencia de la convergencia en muchas de sus políticas (ya sea estableciéndolas o conservándolas) que los hace casi indistintos para los electorados de centro con perfiles ideológicos bajos y orientados a resultados. En ese clima, los factores externos al sistema político adquieren una significación especial a efectos de la toma de decisiones.

La imagen de partido tiende a permanecer estable por periodos prolongados de tiempo, modificándose según las políticas que se propone, así como por la imagen que los medios de comunicación trasmiten de ellos (Sanders, 1988; González y Novo, 2011). En la sociedad de la información, dónde la percepción de la realidad política viene intensamente mediada por el filtro informativo, los medios de comunicación ejercen un papel muy significativo en la modificación y difusión de una imagen de partido, llegando a generar movilización o desmovilización electoral (Alaminos y Penalva, 2010).

En este estudio se va a analizar la valoración de la competencia o capacidad del Partido Popular y del Partido Socialista Obrero Español para gestionar o afrontar diversos temas. En el caso que nos ocupa, es evidente que el Partido Popular y el Partido Socialista Obrero Español han sido durante muchos años los dos partidos en España con mayor presencia electoral. Desde 1982 se han alternado en el gobierno nacional, como partidos mayoritarios. Esta realidad tiene como consecuencia que las encuestas durante varias legislaturas han preguntado especifica o preferentemente por el Partido Popular o el Partido Socialista Obrero Español como referencia de imágenes de partido. Solamente en las últimas elecciones las encuestas preelectorales han flexibilizado la relación entre temas y partidos, dando pie a la incorporación de otros diferentes al Partido Popular o el Partido Socialista Obrero Español. 
En relación con los perfiles temáticos en los que se consideran más potentes a cada uno de los partidos, y exclusivamente considerando la capacidad o gestión del Partido Popular y del Partido Socialista Obrero Español, cabe señalar como análisis anteriores de la evolución del apoyo electoral a los dos partidos (Alaminos, A y Alaminos P, 2017) en base del voto retrospectivo, mostraba como ambos partidos marcaban una trayectoria de declive. De forma progresiva, desde el 2000 en el caso del Partido Popular y desde 2004 para el Partido Socialista Obrero Español, se inicia un descenso paulatino en la creencia sobre la capacidad de gestión de los dos partidos. Dicha dinámica puede observarse en los gráficos siguientes, a partir de las series trimestrales del CIS, con interpolación lineal.

\section{GRÁFICO 1. Series de intención de voto y valoración actuación/gestión del PP}

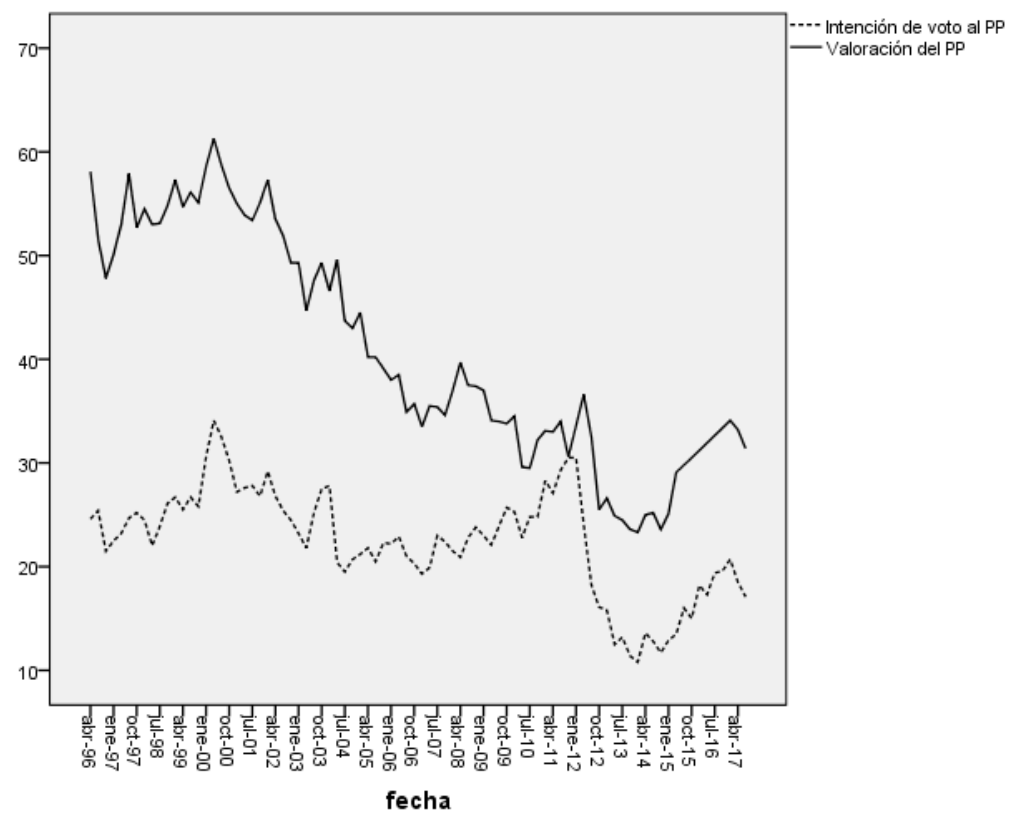

Fuente: Alaminos A. y Alaminos P. Las dinámicas del voto retrospectivo en España (1996-2017). Tendencias, Revista de Sociología. En prensa.

Estas tendencias indican que las capacidades de gestión de los dos partidos eran cuestionadas en la opinión pública, y por lo tanto convergiendo ambos en la debilidad de sus perfiles específicos para gestionar temáticas (políticas). En definitiva, una indiferenciación que permite considerar la extensión de la percepción en la opinión pública de una igual capacidad (o incapacidad) de los dos partidos considerados para gestionar diversas temáticas políticas. En cierto sentido, la difuminación de los perfiles políticos de los dos partidos mayoritarios son una parte sustantiva de la percepción de falta de alternancia real. Particu- 
larmente, tras la expresión de la crisis económica internacional en las políticas sociales en las políticas del gobierno socialista a partir de 2009.

\section{GRÁFICO 2. Series de intención de voto y valoración actuación/gestión del PSOE}

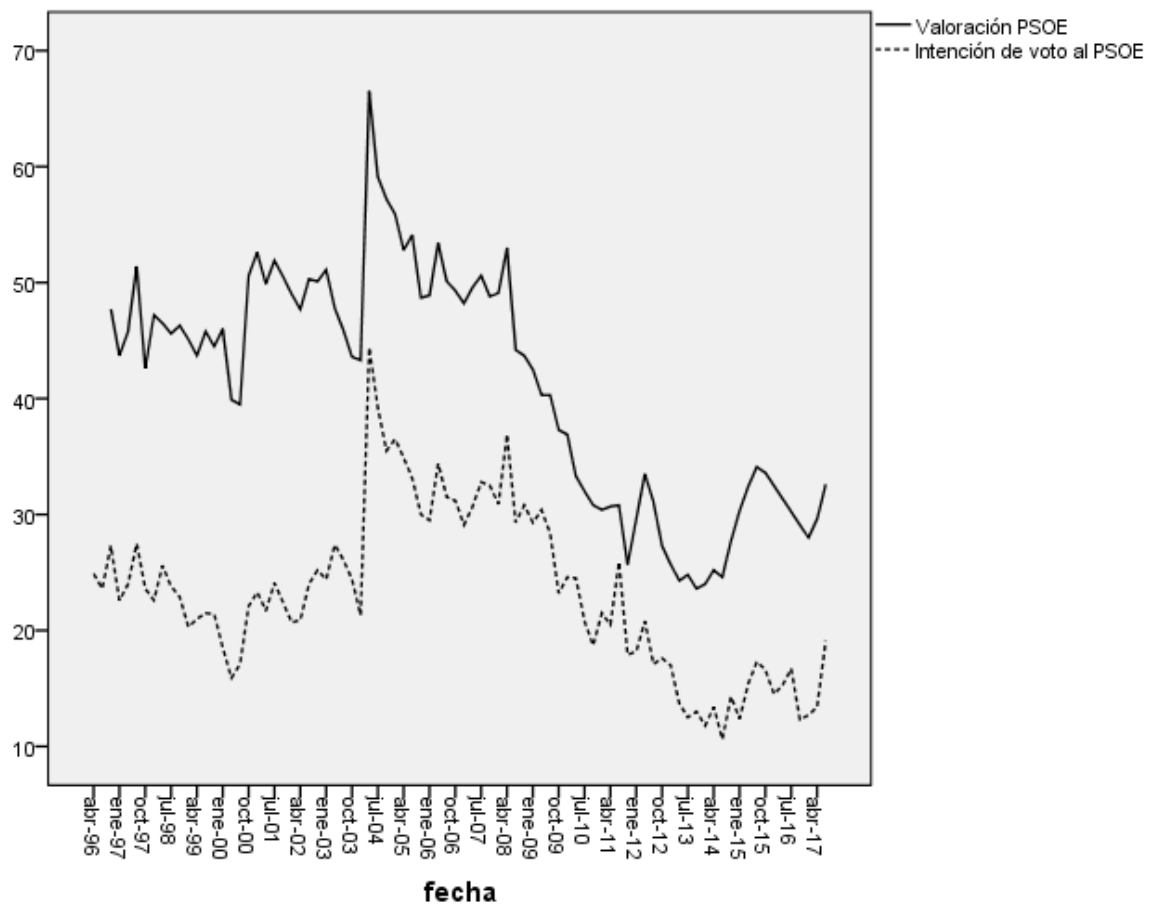

Fuente: Alaminos A. y Alaminos P. Las dinámicas del voto retrospectivo en España (1996-2017). Tendencias, Revista de Sociología. En prensa.

\section{HIPÓTESIS, DATOS y ANÁLISIS.}

En esta investigación, y a partir de las preguntas existentes en varias de las encuestas preelectorales del CIS, sobre qué partidos se perciben más eficaces o competentes para gestionar diferentes tipos de temas, se responden a las siguientes cuestiones. ¿Existen políticas para las que cada partido tiene un peso más específico? ¿Qué temas (políticas) se consideran más diferenciados en la competencia de gestión (imagen) de los dos partidos? De existir, ¿Cuáles son las que corresponden al Partido Popular y cuáles al Partido Socialista Obrero Español? En ese sentido, ¿Existe algún criterio de contenido ideológico que asocie temáticas y partidos? ¿Cómo evoluciona la indiferenciación/diferenciación de competencia en la imagen de los dos partidos? ¿Se produce una tendencia de convergencia para algunos temas? ¿Y en conjunto de las "imágenes de partido" del PP y del PSOE? En definitiva, el objetivo es explorar las diferenciaciones en 
los perfiles de la "imagen de partido" en los dos partidos (Partido Popular y Partido Socialista Obrero Español) entre 1996 y 2015, con la finalidad de evaluar su distancia según la opinión pública española.

De acuerdo con los estudios previos, la hipótesis de referencia plantea una tendencia de indiferenciación entre los perfiles de partido del Partido Popular y del Partido Socialista Obrero Español para la población general. No obstante, los perfiles están distanciados de forma significativa para determinados segmentos, como son los definidos por la intención de voto. Precisamente, dado que la intención de voto sí discrimina entre ellos al valorar la funcionalidad global del Partido Popular y el Partido Socialista Obrero Español, puede utilizarse como elemento de validación prospectiva en la imputación de probabilidad de voto entre los electores indecisos (Alaminos, 1994,1996, 2015). Este análisis excede el espacio y objeto del presente texto.

Se han considerado cinco encuestas preelectorales, administradas "cara a cara", con información estadísticamente significativa a nivel nacional, realizadas por el Centro de Investigaciones Sociologías en 1996, 2000, 2008, 2011 y 2015². Del análisis de las operativizaciones utilizadas se observa que se han empleado tres procedimientos diferentes para conocer la imagen temática de los partidos. En definitiva, atribuir una mayor o menor competencia a los partidos para solucionar diferentes temas define la imagen pública que estos tienen. Así, en 1996: "A continuación voy a mencionarle una serie de objetivos a conseguir en nuestro país en los próximos años. Querría que me dijera, para cada uno de ellos qué partido, Partido Popular o Partido Socialista Obrero Español, cree Vd. Que puede aportar mejores soluciones para conseguir...". En la encuesta de 2000, "Y en relación con cada uno de estos temas, ¿cree que si hubiese estado el PSOE en el Gobierno lo hubiera hecho mejor, igual o peor?". En 2008, "Y en relación con cada uno de estos temas, ¿cree que si hubiese estado el PP en el Gobierno lo hubiera hecho mejor, igual o peor?". El cuestionario de 2011 frasea la pregunta de un modo diferente, ofreciendo además la posibilidad de codificar la respuesta espontánea "otros partidos". "Y en general, iqué partido político, el PSOE o el PP, considera que está más capacitado para afrontar cada uno de los siguientes temas?". Finalmente, en 2015, modifica el fraseo suprimiendo la referencia al PP o PSOE "Y en general, ¿qué partido político, considera Ud. que está más capacitado para afrontar cada uno de los siguientes temas?" permitiendo que el entrevistado mencione el partido de forma espontánea. De las cinco preguntas, correspondientes a 2015 la que excluye del enunciado la mención expresa al PP o al PSOE, lo que introduce un sesgo difícil de evaluar en términos de comparabilidad con las otras preguntas (Alaminos, 1991, 2012; Alaminos y Castejón, 2006; Francés et al, 2014). No obstante, la información que aporta es especialmente interesante dado el escenario de ruptura de bipartidismo y por lo tanto la

\footnotetext{
1 Los datos referidos a su ficha técnica detallada pueden ser consultados en la página web del centro (http://www.cis.es/cis/opencms/ES/1_encuestas/catalogoencuestas.html). Se trata de los estudios ES2207 (1996), ES2382 (2000), ES2750 (2008), ES2915 (2011) y el ES3117 (2015).
} 
incorporación de otros partidos como objetos políticos con su propia "imagen de partido". En términos estrictos, la modificación puede influir en la magnitud de sus perfiles y en menor grado en la comparación entre ambos.

Las diferencias en la operativización dificultan la comparación en términos de evolución temporal. Básicamente, los cambios han introducido una mayor libertad para que el entrevistado decida la relación entre políticas y partidos, incluyendo en 2015 la posibilidad de otros diferentes al Partido Popular o el Partido Socialista Obrero Español. Así, en la formulación de 1996, 2000 y 2008, la pregunta de referencia considera dos partidos, Partido Popular y Partido Socialista Obrero Español, planteando en términos comparativos cuál de los dos es más eficaz para dar respuesta a dichos problemas. La formulación de la pregunta se modifica en el 2011, y si bien en su fraseo enuncia expresamente el Partido Popular y el Partido Socialista Obrero Español, deja abierta la opción (no ofrecida al entrevistado) de responder otros partidos. En las versiones de $2000 \mathrm{y}$ 2008 dicha posibilidad se acumula dentro de diferentes categorías ("igual los dos", "no sabe" o "no contesta"). En todo caso, los porcentajes de respuesta referidos a "otros partidos" en la encuesta de 2011 son muy reducidos. En la pregunta de 2015, se interroga sobre qué partido considera más capacitado para afrontar el listado de temas que se propone. No se ofrece expresamente ningún partido, quedando abierta la posibilidad de mencionar cualquiera. Los años 1996, 2000, 2008 y 2011 son los que mayor comparabilidad muestran, al presentar a su evaluación expresamente al Partido Popular y al Partido Socialista Obrero Español, siendo la más abierta la encuesta de 2015.

La diferenciación entre los perfiles políticos de los partidos se puede considerar desde un punto de vista conjunto (las distancias entre sus perfiles) o evaluados en función a temáticas concretas. Vamos en primer lugar a considerar de forma específica cada una de las temáticas en términos descriptivos para el conjunto de la población.

En 1996 prácticamente dos de cada tres entrevistados atribuían un mayor o menor peso del Partido Popular o del Partido Socialista en determinadas políticas. Así, el Partido Socialista mostraba un perfil más elevado en la reducción de las "desigualdades sociales", "la mejora en las prestaciones sociales", "asegurar las pensiones", "la mejora de la calidad en la enseñanza pública" o en "mejorar la calidad de la sanidad pública". Con una mayor atribución de importancia al perfil del Partido Popular, destacaba su potencial para "mejorar la seguridad ciudadana" o "luchar contra la droga". En definitiva, se aprecia con bastante claridad como el Partido Socialista Obrero Español presentaba una imagen pública de defensa y desarrollo del bienestar social, mientras que el Partido Popular destacaba en los aspectos de seguridad. En definitiva, un cierto reparto de papeles que permitía a cada uno de ellos presentar un centro de gravedad propio. 
TABLA 1. Qué partido es más competente para gestionar políticamente diversos temas (1996)

\begin{tabular}{|l|c|c|c|c|c|c|}
\hline & PP & PSOE & \multicolumn{1}{|c|}{ Ninguno } & NS & NC \\
\hline & \multicolumn{5}{|c|}{ \% la fila } \\
\hline Reducir el paro & 32.5 & 25.4 & 23.0 & 17.7 & 1.4 \\
\hline Mejorar la seguridad ciudadana & 40.5 & 24.8 & 14.0 & 19.3 & 1.5 \\
\hline Mejorar las prestaciones sociales & 22.7 & 43.5 & 13.0 & 19.3 & 1.5 \\
\hline Eliminar la corrupción & 37.6 & 19.2 & 23.7 & 17.9 & 1.6 \\
\hline Mejorar la calidad de la enseñanza pública & 24.0 & 41.6 & 11.4 & 21.4 & 1.6 \\
\hline Reducir las desigualdades sociales & 20.1 & 42.7 & 17.0 & 18.8 & 1.4 \\
\hline Luchar contra la droga & 34.0 & 26.6 & 17.1 & 20.6 & 1.7 \\
\hline $\begin{array}{l}\text { Conseguir un pacto social con empresarios y y } \\
\text { sindicatos }\end{array}$ & 29.4 & 30.8 & 14.8 & 23.4 & 1.4 \\
\hline $\begin{array}{l}\text { Mantener buenas relaciones con las Comuni- } \\
\text { dades Autónomas }\end{array}$ & 25.0 & 37.0 & 11.7 & 24.6 & 1.7 \\
\hline $\begin{array}{l}\text { Mejorar la calidad de la asistencia sanitaria } \\
\text { pública }\end{array}$ & 25.1 & 39.8 & 12.8 & 20.7 & 1.7 \\
\hline Asegurar las pensiones & 22.1 & 40.2 & 15.6 & 20.0 & 2.1 \\
\hline
\end{tabular}

Fuente: Estudio ES2207 del CIS (1996)

En términos de porcentaje, el $43.5 \%$ atribuye una mayor capacidad para "mejorar las prestaciones sociales" al Partido Socialista Obrero Español, un 41.6\% "mejorar la calidad de la enseñanza pública", el 42.7\% "reducir las desigualdades sociales", el 40.2\% "asegurar las pensiones" y un 39.8\% "mejorar la calidad de la asistencia sanitaria pública". En el caso del Partido Popular el 40.5\% le consideraba más capacitado para "mejorar la seguridad ciudadana", y un 34\% "luchar contra las drogas". En cierto sentido los dos partidos mostraban unos perfiles bien definidos con respecto a dos dimensiones diferenciadas como son el bienestar social o la seguridad.

Sin embargo, considerando sus perfiles globales en relación con su capacidad para las diferentes políticas, un $28.4 \%$ consideraba al Partido Popular capacitado, siendo un 33.7\% para el caso del Partido Socialista Obrero Español. Así, si bien es cierto que para políticas muy concretas las diferencias entre los perfiles de los partidos eran significativas, tomadas en conjunto la diferencia de los perfiles entre los dos partidos integradas las diferentes políticas (temas) no era especialmente elevada. Debe de considerarse que los porcentajes de "no sabe" o "no contesta", así como la opción de "ninguno" ejerce un efecto techo sobre las 
distancias máximas que puede alcanzar entre sí los dos partidos (Alaminos et al. 2015).

En el año 2000, antes de las elecciones, la atribución temática a los dos partidos había modificado de forma significativa su estructura. Así, mientras que en 1996 tanto el Partido Popular, Partido Socialista Obrero Español mostraban porcentajes altos de atribución temática, en la encuesta preelectoral del año 2000 los porcentajes más elevados corresponde a la opción "igual los dos". Cabe plantear el hecho de que sustituir "ninguno", por "igual los dos" introduce la ambigüedad tanto en sentido positivo como negativo. Es decir, la afirmación "igual los dos" es válida tanto para afirmar la incompetencia de los dos partidos con respecto a la temática propuesta, como su posible competencia. No obstante, resulta evidente por el fraseo que la intención del investigador era poner en un plano de igualdad en términos de competencia de gestión a los dos partidos.

La consecuencia de estos elevados porcentajes indicando la indiferenciación de los dos partidos en relación con su competencia para gestionar los temas propuestos, es que los porcentajes que atribuyen una mayor competencia a alguno de estos partidos en concreto son bastante más reducidos que para el año 1996. En la práctica, solamente un $36.9 \%$ de los entrevistados atribuyen una mayor competencia al Partido Popular o al Partido Socialista. El resto de los entrevistados eligieron las opciones "igual los dos", "no sabe", "no contesta". Desde el punto de vista temático, cabe señalar que en todas las políticas preguntadas es el Partido Popular el que recogía un porcentaje más elevado. Destaca en especial la atribución de una mayor capacidad Partido Popular para gestionar la "economía", el "empleo", el "terrorismo" y la "seguridad ciudadana". A su perfil tradicional basado en el concepto de seguridad se añadía en ese momento los atributos relacionados con la generación de empleo y el desarrollo económico. Asimismo, si bien el Partido Popular mantiene aún unas marcas propias apoyadas sobre la noción de seguridad, en el resto de los temas se produce una aproximación significativa a los característicos del Partido Socialista Obrero Español. En ese sentido, en el año 2000 se aprecia una aproximación entre los perfiles de los dos partidos, con un incremento muy significativo (de hecho, los porcentajes más elevados) por el cual se pone en plano de igualdad las capacidades de ambos partidos. 
TABLA 2. Qué partido es más competente para gestionar políticamente diversos temas (2000)

\begin{tabular}{|l|r|r|r|r|r|}
\hline & \multicolumn{1}{|c|}{$\begin{array}{c}\text { Igual los } \\
\text { dos }\end{array}$} & \multicolumn{1}{c|}{ PP } & \multicolumn{2}{c|}{ N.S. } & \multicolumn{1}{c|}{ N.C. } \\
\cline { 2 - 6 } & \multicolumn{5}{|c|}{$\%$ de la fila } \\
\hline El empleo & $13,1 \%$ & $38,7 \%$ & $28,3 \%$ & $19,1 \%$ &, $8 \%$ \\
\hline La educación & $17,5 \%$ & $40,3 \%$ & $21,4 \%$ & $20,0 \%$ &, $8 \%$ \\
\hline La sanidad & $15,7 \%$ & $41,2 \%$ & $23,4 \%$ & $18,8 \%$ &, $8 \%$ \\
\hline La economía & $10,9 \%$ & $38,7 \%$ & $30,3 \%$ & $19,2 \%$ &, $8 \%$ \\
\hline La integración en Europa & $13,4 \%$ & $43,0 \%$ & $21,4 \%$ & $21,3 \%$ &, $9 \%$ \\
\hline El terrorismo & $12,2 \%$ & $44,7 \%$ & $22,7 \%$ & $19,5 \%$ &, $9 \%$ \\
\hline La seguridad ciudadana & $10,6 \%$ & $47,7 \%$ & $21,4 \%$ & $19,3 \%$ &, $9 \%$ \\
\hline La inmigración & $17,5 \%$ & $40,4 \%$ & $20,1 \%$ & $21,1 \%$ &, $9 \%$ \\
\hline El desarrollo autonómico & $13,6 \%$ & $42,4 \%$ & $21,0 \%$ & $22,0 \%$ &, $9 \%$ \\
\hline $\begin{array}{l}\text { La protección del medio } \\
\text { ambiente }\end{array}$ & $15,5 \%$ & $44,4 \%$ & $19,0 \%$ & $20,2 \%$ &, $8 \%$ \\
\hline
\end{tabular}

Fuente: Estudio ES2382 del CIS (2000)

Carecemos de datos para el año 2004, dado que el preelectoral de esas elecciones no incluía la pregunta que se está utilizando para este análisis. Ya en las elecciones de 2008, un primer aspecto llamativo es que si bien en el año 2000 el Partido Popular se percibía como el más competente (en mayor o menor grado) para la gestión de todos los temas planteados al entrevistados, en el año 2008 sucede precisamente lo contrario. El Partido Socialista Obrero Español es considerado el más competente (en mayor o menor grado) para resolver los diferentes temas. Esto en sí mismo expresa una diferencia importante con respecto a las elecciones de 1996. En 1996 existía una atribución diferenciada de una mayor o menor capacidad a cada uno de los dos partidos. En el año 2000 la atribución más general era para el partido en el gobierno, es decir Partido Popular. En el año 2008, la atribución de competencias más general es para Partido Socialista Obrero Español, que se encontraba en el gobierno en aquel entonces. Cabe pensar que uno de los factores que intervienen en la valoración temática es que el partido se encuentre o no gobernando, si bien la ausencia de datos en 2004 impide establecer un patrón definido.

En la encuesta preelectoral de 2008, como se ha afirmado, los porcentajes más elevados de atribución de una mayor competencia se encuentran en el Partido Socialista Obrero Español. Temáticamente, destacan en particular la "política social", la "defensa del medio ambiente", la "vivienda", el "Estado de las autonomías", y la "sanidad", la "educación" y el "empleo". Como hemos visto anteriormente, temas característicos del Partido Socialista Obrero Español en el 1996. Existe, no obstante, una proximidad elevada entre los dos partidos en lo 
que se refiere a la "economía", el "terrorismo", la "seguridad ciudadana", la "inmigración”, “Unión Europea” o "política exterior".

TABLA 3. Qué partido es más competente para gestionar políticamente diversos temas (2008)

\begin{tabular}{|c|c|c|c|c|c|}
\hline & $\mathrm{PP}$ & $\begin{array}{l}\text { Igual los } \\
\text { dos }\end{array}$ & PSOE & N.S. & N.C. \\
\hline & \multicolumn{5}{|c|}{$\%$ de la fila } \\
\hline El empleo & $17,5 \%$ & $35,5 \%$ & $28,3 \%$ & $17,8 \%$ & $9 \%$ \\
\hline La educación & $18,0 \%$ & $33,4 \%$ & $30,1 \%$ & $17,5 \%$ & $1,1 \%$ \\
\hline La sanidad & $15,0 \%$ & $39,3 \%$ & $27,8 \%$ & $16,8 \%$ & $1,2 \%$ \\
\hline La economía & $24,4 \%$ & $31,4 \%$ & $26,5 \%$ & $16,5 \%$ & $1,2 \%$ \\
\hline La Unión Europea & $17,2 \%$ & $34,9 \%$ & $26,2 \%$ & $20,3 \%$ & $1,3 \%$ \\
\hline La política social & $13,1 \%$ & $31,5 \%$ & $35,8 \%$ & $18,3 \%$ & $1,4 \%$ \\
\hline El terrorismo & $22,5 \%$ & $28,7 \%$ & $31,1 \%$ & $16,3 \%$ & $1,3 \%$ \\
\hline La seguridad ciudadana & $19,5 \%$ & $38,3 \%$ & $24,6 \%$ & $16,3 \%$ & $1,3 \%$ \\
\hline La vivienda & $15,6 \%$ & $36,2 \%$ & $30,2 \%$ & $16,7 \%$ & $1,3 \%$ \\
\hline La inmigración & $20,8 \%$ & $30,9 \%$ & $30,3 \%$ & $16,7 \%$ & $1,3 \%$ \\
\hline $\begin{array}{l}\text { El Estado de las Auto- } \\
\text { nomías }\end{array}$ & $17,1 \%$ & $30,8 \%$ & $30,6 \%$ & $20,0 \%$ & $1,4 \%$ \\
\hline El medio ambiente & $11,8 \%$ & $39,8 \%$ & $29,1 \%$ & $18,0 \%$ & $1,3 \%$ \\
\hline La política exterior & $18,7 \%$ & $32,6 \%$ & $27,5 \%$ & $19,8 \%$ & $1,4 \%$ \\
\hline
\end{tabular}

Fuente: Estudio ES2750 del CIS (2008)

Aun con una mayor presencia de ciertos temas para Partido Socialista Obrero Español, si consideramos la respuesta que propone la igualdad de los dos partidos para la gestión de "sanidad", podemos observar cómo para el 39,3\% los dos partidos son igual de competentes, al igual que para el "medio ambiente" (39.8\%), la "seguridad ciudadana" (38.3\%), la "Unión Europea" (34.9\%) o el "empleo" (35.5\%). De hecho, los porcentajes que expresan la idea de que los dos partidos son igual de competentes, y por lo tanto indiferentes con respecto a la gestión de dichos temas, son superiores a los que atribuye una capacidad particular a cualquiera de los dos partidos, con la excepción de la "política social", donde un 35,8\% considera que el Partido Socialista Obrero Español está más capacitado, por un 31.5\% que expresa por igual los dos partidos. Asimismo, en el caso del "terrorismo", con el 31.1\% que de igual modo considera más capacitado al Partido Socialista Obrero Español, siendo el 28.7\% los que piensan que por igual los dos partidos. En ese sentido si bien el Partido Socialista Obrero Español retomó cierto peso en sus perfiles relacionados con las políticas sociales, se encuentra mucho menos diferenciado del Partido Popular en comparación con la situación en 1996. Algo semejante puede decirse con respecto a los 
temas principales del Partido Popular (seguridad y economía) con respecto al Partido Socialista Obrero Español.

En la encuesta preelectoral de 2011 se retoma un fraseo semejante al utilizado en la encuesta de 1996, al desaparecer la opción "ambos por igual" y reaparecer la de "ninguno". Asimismo, se incorpora la codificación de una posible respuesta que proponga como más competente algún otro partido. No obstante, el fraseo sigue destacando en especial el caso del Partido Socialista Obrero Español y del Partido Popular. Esto es algo que se refleja claramente en la estructura de respuestas, dado que los porcentajes de entrevistados que mencionaron algún "otro partido" son siempre inferiores al $4 \%$.

TABLA 4. Qué partido es más competente para gestionar políticamente diversos temas (2011)

\begin{tabular}{|l|c|c|c|r|r|c|}
\hline & PSOE & PP & $\begin{array}{c}\text { Otro } \\
\text { partido }\end{array}$ & Ninguno & N.S. & N.C. \\
\hline & \multicolumn{7}{|c|}{$\%$ de la fila } \\
\hline El empleo & $15,9 \%$ & $37,5 \%$ & $2,7 \%$ & $25,9 \%$ & $16,5 \%$ & $1,5 \%$ \\
\hline La educación & $27,3 \%$ & $30,5 \%$ & $3,0 \%$ & $19,2 \%$ & $18,4 \%$ & $1,4 \%$ \\
\hline La sanidad & $28,5 \%$ & $29,3 \%$ & $2,8 \%$ & $19,1 \%$ & $18,6 \%$ & $1,7 \%$ \\
\hline La economía & $15,0 \%$ & $41,1 \%$ & $2,6 \%$ & $23,4 \%$ & $16,4 \%$ & $1,5 \%$ \\
\hline La Unión Europea & $21,6 \%$ & $32,0 \%$ & $2,8 \%$ & $19,0 \%$ & $22,8 \%$ & $2,0 \%$ \\
\hline La política social & $32,3 \%$ & $25,9 \%$ & $3,1 \%$ & $18,2 \%$ & $18,8 \%$ & $1,7 \%$ \\
\hline La seguridad ciudadana & $23,2 \%$ & $33,1 \%$ & $2,4 \%$ & $19,2 \%$ & $19,8 \%$ & $2,2 \%$ \\
\hline La vivienda & $21,4 \%$ & $31,5 \%$ & $3,1 \%$ & $22,8 \%$ & $19,4 \%$ & $1,8 \%$ \\
\hline La inmigración & $22,6 \%$ & $34,7 \%$ & $2,9 \%$ & $20,4 \%$ & $17,7 \%$ & $1,7 \%$ \\
\hline $\begin{array}{l}\text { El Estado de las auto- } \\
\text { nomías }\end{array}$ & $22,0 \%$ & $30,7 \%$ & $3,4 \%$ & $20,1 \%$ & $22,1 \%$ & $1,7 \%$ \\
\hline El medio ambiente & $28,3 \%$ & $24,9 \%$ & $4,0 \%$ & $19,3 \%$ & $21,4 \%$ & $2,1 \%$ \\
\hline La política exterior & $21,8 \%$ & $33,1 \%$ & $2,6 \%$ & $18,6 \%$ & $21,8 \%$ & $1,9 \%$ \\
\hline $\begin{array}{l}\text { La igualdad entre hom- } \\
\text { bres y mujeres }\end{array}$ & $35,1 \%$ & $23,4 \%$ & $3,0 \%$ & $17,8 \%$ & $18,5 \%$ & $2,1 \%$ \\
\hline Las infraestructuras & $23,7 \%$ & $31,0 \%$ & $2,7 \%$ & $18,8 \%$ & $21,3 \%$ & $2,4 \%$ \\
\hline
\end{tabular}

Fuente: Estudio ES2915 del CIS (2011)

La encuesta preelectoral de 2011 nos refiere a una situación de crisis social y económica muy profunda. El Partido Socialista Obrero Español tras dos años de profundos recortes sociales, llega a unas elecciones muy debilitado. En dicho contexto, el Partido Popular sostenía un discurso muy crítico con el Partido Socialista Obrero Español, ofertando la posibilidad de cambiar las políticas que imponía la Unión Europea. En ese sentido, tras varios años de recortes, el Partido Popular en su discurso político proponía dejar de hacerlo. Al mismo tiempo, los niveles de desempleo habían alcanzado unas tasas tremendamente elevadas, con el consecuente impacto sobre la vida cotidiana de los españoles. Cuando consideramos la percepción de los partidos con respecto a la mejor gestión de 
diferentes temas, es importante recordar el contexto de crisis y la sugerencia de esperanza que formaba parte de la propaganda y discurso electoral del Partido Popular. En esta ocasión, tal y como observamos en el año 2000, el Partido Popular eleva su perfil con respecto Partido Socialista Obrero Español en dos temas fundamentales: la "economía" y el "empleo". Con menor diferencia aparecen la "gestión de la inmigración", la "política exterior" o la "Unión Europea", así como la "vivienda". El Partido Socialista Obrero Español conserva exclusivamente como rasgo distintivo el de la "igualdad entre hombres y mujeres", una dimensión a la que los gobiernos del presidente Zapatero habían prestado una atención especial desde el punto de vista legislativo. Así, un 41.1\% de los entrevistados considera que el Partido Popular en 2011 era más competente para gestionar la "economía", o el "empleo" (37.5\%). Con la excepción de la "política social" donde un 25\% considera que el PP es más competente que el PSOE, (un $32 \%$ opina que lo es el Partido Socialista), el "medio ambiente" (28\% Partido Socialista por un 25\% el Partido Popular) o la "igualdad entre hombres y mujeres" ya mencionada (35\% el Partido Socialista, y un 23\% Partido Popular), para todos los demás temas es el Partido Popular el percibido como más competente. Sin embargo, con la excepción de la "economía" y el "empleo", en todos los demás temas se encuentran muy próximos los dos partidos. Nuevamente la diferenciación entre ambos partidos se encuentra limitada o restringida a temas puntuales específicos y con una diferencia entre porcentajes muy reducida.

Cabe afirmar una convergencia entre ambos perfiles, solamente matizada por las crisis del contexto que otorga una mayor relevancia dada la coyuntura a temas muy específicos como son el empleo o la economía. Asimismo, en comparación con la opción "ninguno" (que también aparecía en la encuesta de 1996) se aprecia un incremento significativo en el año 2011 para todos los temas, al igual que en la opción de "no sabe". En definitiva, controlando el efecto de la crisis económica, se observa una mayor proximidad entre los dos partidos en relación con todos los temas considerados, junto con un incremento en la opción que opina que "ninguno" de los dos partidos es realmente competente para gestionar los temas propuestos.

Los datos de la encuesta preelectoral de 2015 incorporan las dos novedades que habían aparecido por separado en frases anteriores. Así, se conserva la categoría que "ninguno", y la posibilidad de proponer otros partidos diferentes del Partido Socialista Obrero Español o el Partido Popular. Al no estar mencionados expresamente en la pregunta, cualquier partido político es una opción de respuesta viable. Este hecho es especialmente significativo en la medida que en ese momento al menos dos nuevos partidos se habían incorporado de forma significativa al escenario político nacional, junto a Izquierda Unida. Es el caso del partido Podemos y del partido Ciudadanos. De hecho, en la práctica, y con significación en términos estadísticos, al Partido Popular y el Partido Socialista Obrero Español se le añaden Izquierda Unida, Ciudadanos y Podemos, perma- 
neciendo en la categoría "Otros" un agregado de partidos sin peso específico. En la medida en que este estudio se concentra en las imágenes del Partido Popular y del Partido Socialista Obrero Español, la aparición de otros partidos actúa complementando la capacidad de estos en los diferentes temas. No obstante, sigue siendo factible comparar el grado de diferenciación tanto temáticamente como agrupada entre los dos partidos que son objeto de esta investigación.

TABLA 5. Qué partido es más competente para gestionar políticamente diversos temas (2015)

\begin{tabular}{|l|c|c|c|c|c|c|c|c|c|c|}
\hline & PP & PSOE & IU & $\begin{array}{c}\text { Ciudada- } \\
\text { nos }\end{array}$ & $\begin{array}{c}\text { Pode- } \\
\text { mos }\end{array}$ & $\begin{array}{c}\text { Otros } \\
\text { Nin- } \\
\text { guno }\end{array}$ & N.S. & N.C. \\
\hline & \multicolumn{7}{|c|}{ la fila } \\
\hline El empleo & 17,8 & 14,5 & 2,6 & 9,5 & 8,2 & 4,1 & 17,5 & 23,1 & 2,7 \\
\hline La educación & 16,4 & 17,9 & 2,9 & 9,0 & 9,4 & 4,6 & 14,8 & 22,6 & 2,4 \\
\hline La sanidad & 16,9 & 19,1 & 2,9 & 8,6 & 8,8 & 4,5 & 14,5 & 22,4 & 2,3 \\
\hline La economía & 21,0 & 13,4 & 2,2 & 9,7 & 7,7 & 4,2 & 15,6 & 23,7 & 2,5 \\
\hline La Unión Europea & 20,2 & 13,8 & 1,9 & 7,7 & 8,4 & 3,9 & 14,4 & 27,1 & 2,6 \\
\hline La política social & 14,8 & 18,4 & 3,1 & 8,2 & 11,8 & 4,5 & 13,8 & 23,0 & 2,4 \\
\hline La seguridad ciudadana & 20,2 & 14,8 & 2,3 & 8,1 & 7,4 & 4,3 & 14,2 & 26,2 & 2,5 \\
\hline La vivienda & 15,3 & 16,2 & 2,8 & 8,5 & 11,4 & 4,5 & 14,4 & 24,4 & 2,5 \\
\hline La inmigración & 16,8 & 15,3 & 2,9 & 8,1 & 10,0 & 4,1 & 14,8 & 25,5 & 2,5 \\
\hline $\begin{array}{l}\text { El Estado de las autono- } \\
\text { mías }\end{array}$ & 16,8 & 14,1 & 2,4 & 9,5 & 7,8 & 5,1 & 14,6 & 27,1 & 2,6 \\
\hline El medio ambiente & 15,8 & 14,6 & 3,5 & 7,5 & 9,8 & 5,4 & 14,1 & 26,7 & 2,6 \\
\hline La política exterior & 20,6 & 14,7 & 1,9 & 7,7 & 7,5 & 4,0 & 14,0 & 27,0 & 2,6 \\
\hline $\begin{array}{l}\text { La igualdad entre hom- } \\
\text { bres y mujeres }\end{array}$ & 15,0 & 18,1 & 3,4 & 8,2 & 10,6 & 4,5 & 13,9 & 23,7 & 2,6 \\
\hline Las infraestructuras & 19,1 & 15,3 & 2,2 & 8,0 & 7,3 & 4,5 & 14,1 & 26,9 & 2,6 \\
\hline
\end{tabular}

Fuente: Estudio ES3117 del CIS (2015)

En ese sentido la atribución de capacidad política al Partido Popular o al Partido Socialista Obrero Español en el listado de temas propuesto se hace prácticamente indistinta con diferencias entre ellos con valores máximos inferiores en todo caso al $8 \%$. No existe ningún tema que pueda considerarse un atributo específico diferenciador de un partido con respecto al otro. Ya sea en "política social", o en "seguridad ciudadana" el grado de diferenciación es realmente mínimo. No obstante, cabe señalar que, en cualquier caso, los porcentajes que 
atribuyen una mayor capacidad en estas temáticas al Partido Popular o al Partido Socialista Obrero Español son superiores a los que se atribuyen a otros partidos alternativos. Estos entran con perfiles bastante genéricos, de amplio espectro temático, con la excepción de Podemos donde destaca una mayor capacidad en términos de "política social", "vivienda", o "igualdad entre hombre y mujer".

En términos de comparación de perfiles diferenciados entre el Partido Popular y el Partido Socialista Obrero Español, los datos de 2015 ofrecen el mayor grado de indiferenciación entre los dos partidos. No existe ninguna temática que pueda definirse como un rasgo distintivo ya sea del Partido Popular por el Partido Socialista Obrero Español. La opción "ninguno" se ve afectada por la introducción de nuevos partidos reduciendo su peso con relación a la encuesta de 2011.

Estos aspectos que se han comentado hasta el momento se aprecian con mayor nitidez cuando se evalúan las distancias conjuntas entre los temas que forman los perfiles de los dos partidos. Vamos a utilizar la distancia euclidiana al cuadrado para optimizar las diferencias, y posteriormente se ha dividido por el número de temas a efectos de relativizar y hacer comparables las distancias promedio, independientemente del número de temas a valorar. De este modo se compensa la presencia de un número diferente de temas según el año considerado. Seguidamente, se normaliza entre cero y uno para facilitar la comprensión de la evolución del proceso tomando como referencia primero la diferencia máxima teórica que es posible establecerse entre los perfiles de los dos partidos. Asimismo, se calcula un segundo coeficiente utilizando como valor de distancia máxima posible el observado en 1996, empleando la máxima distancia empírica como referencia (Alaminos et al., 2015). Ciertamente, la diferencia entre el rango teórico y el empírico es bastante importante, dado que en el teórico se produce el efecto techo de la no respuesta o del "ninguno". Sin embargo, aun corrigiendo por un máximo empírico, la distancia entre los perfiles de los dos partidos continúa siendo muy baja, y con una tendencia evidente a converger y perder diferenciación, como planteaba las tesis de Wattenberg $(1986 ; 2000)$.

Las tablas siguientes muestran las distancias temáticas entre el Partido Popular y el Partido Socialista Obrero Español, junto con el cálculo de la distancia euclidiana al cuadrado y la distancia euclidiana al cuadrado corregida por el número de temas. Como se mencionó anteriormente, dado que los temas varían en número entre las diferentes elecciones, se ha corregido dividiendo por el total de temas en cada año, estimando con ello un promedio de distancia euclidiana cuadrada. 
TABLA 6. 1996: Distancia euclidiana cuadrada entre los perfiles del PP y del PSOE $^{2}$

\begin{tabular}{|l|r|r|}
\hline & Distancia & $\begin{array}{r}\text { Distancia eu- } \\
\text { clidiana al } \\
\text { cuadrado }\end{array}$ \\
\hline Reducir el paro & 7,1 & 50,41 \\
\hline Mejorar la seguridad ciudadana & 15,7 & 246,49 \\
\hline Mejorar las prestaciones sociales & $-20,8$ & 432,64 \\
\hline Eliminar la corrupción & 18,4 & 338,56 \\
\hline Mejorar la calidad de la enseñanza pública & $-17,6$ & 309,76 \\
\hline Reducir las desigualdades sociales & $-22,6$ & 510,76 \\
\hline Luchar contra la droga & 7,4 & 54,76 \\
\hline $\begin{array}{l}\text { Conseguir un pacto social con empresarios y } \\
\text { sindicatos }\end{array}$ & $-1,4$ & 1,96 \\
\hline $\begin{array}{l}\text { Mantener buenas relaciones con las Comuni- } \\
\text { dades Autónomas }\end{array}$ & -12 & 239,36 \\
\hline $\begin{array}{l}\text { Mejorar la calidad de la asistencia sanitaria } \\
\text { pública }\end{array}$ & $-14,7$ & 327,61 \\
\hline Asegurar las pensiones & $-18,1$ & 2633,04 \\
\hline Distancia euclidiana al cuadrado (1996) & & 216,09 \\
\hline Distancia euclidiana cuadrada ajustada & & \\
\hline
\end{tabular}

Fuente: elaboración propia sobre datos Estudio ES2207 del CIS (1996)

\footnotetext{
${ }^{2}$ Los positivos son los temas con ventaja para el Partido Popular mientras que los negativos son temas con ventaja en la imagen del Partido Socialista Obrero Español
} 
TABLA 7. 2000: Distancia euclidiana cuadrada entre los perfiles del PP y del PSOE

\begin{tabular}{|l|r|r|}
\hline & $\begin{array}{c}\text { Distan- } \\
\text { cia }\end{array}$ & $\begin{array}{r}\text { Distancia euclidiana } \\
\text { al cuadrado }\end{array}$ \\
\hline El empleo & 15,20 & 231,04 \\
\hline La educación & 3,90 & 15,21 \\
\hline La sanidad & 7,70 & 59,29 \\
\hline La economía & 19,40 & 376,36 \\
\hline El terrorismo & 10,50 & 110,25 \\
\hline La seguridad ciudadana & 10,80 & 116,64 \\
\hline La inmigración & 2,60 & 6,76 \\
\hline El desarrollo autonómico & 7,40 & 54,76 \\
\hline $\begin{array}{l}\text { La protección del medio am- } \\
\text { biente }\end{array}$ & 3,50 & 12,25 \\
\hline La integración en Europa & 8,00 & 64,00 \\
\hline Distancia euclidiana al cuadrado (2000) & & 1046,56 \\
\hline Distancia euclidiana cuadrada ajustada & 104,66 \\
\hline
\end{tabular}

Fuente: elaboración propia sobre datos Estudio ES2382 del CIS (2000) 
TABLA 8. 2008: Distancia euclidiana cuadrada entre los perfiles del PP y del PSOE

\begin{tabular}{|l|r|r|}
\hline & $\begin{array}{c}\text { Distan- } \\
\text { cia }\end{array}$ & $\begin{array}{r}\text { Distancia euclidiana } \\
\text { al cuadrado }\end{array}$ \\
\hline El empleo & $-10,80$ & 116,64 \\
\hline La educación & $-12,10$ & 146,41 \\
\hline La sanidad & $-12,80$ & 163,84 \\
\hline La economía & $-2,10$ & 4,41 \\
\hline El terrorismo & $-8,60$ & 73,96 \\
\hline La seguridad ciudadana & $-5,10$ & 26,01 \\
\hline La inmigración & $-9,50$ & 90,25 \\
\hline El Estado de las Autonomías & $-13,50$ & 182,25 \\
\hline El medio ambiente & $-17,30$ & 299,29 \\
\hline La Unión Europea & $-9,00$ & 81,00 \\
\hline La política social & $-22,70$ & 515,29 \\
\hline La vivienda & $-14,60$ & 213,16 \\
\hline La política exterior & $-8,80$ & 77,44 \\
\hline Distancia euclidiana al cuadrado $(2008)$ & 1989,95 \\
\hline Distancia euclidiana cuadrada ajustada & 153,07 \\
\hline
\end{tabular}

Fuente: elaboración propia sobre datos Estudio ES2750 del CIS (2008) 
TABLA 9. 2011: Distancia euclidiana cuadrada entre los perfiles del PP y del PSOE

\begin{tabular}{|c|c|c|}
\hline & $\begin{array}{l}\text { Distan- } \\
\text { cia }\end{array}$ & $\begin{array}{l}\text { Distancia eucli- } \\
\text { diana } \\
\text { al cuadrado }\end{array}$ \\
\hline El empleo & 21,60 & 466,56 \\
\hline La educación & 3,20 & 10,24 \\
\hline La sanidad & 0,80 & 0,64 \\
\hline La economía & 26,10 & 681,21 \\
\hline La seguridad ciudadana & 9,90 & 98,01 \\
\hline La inmigración & 12,10 & 146,41 \\
\hline El Estado de las autonomías & 8,70 & 75,69 \\
\hline El medio ambiente & $-3,40$ & 11,56 \\
\hline La Unión Europea & 10,40 & 108,16 \\
\hline La política social & $-6,40$ & 40,96 \\
\hline La vivienda & 10,10 & 102,01 \\
\hline La política exterior & 11,30 & 127,69 \\
\hline $\begin{array}{l}\text { La igualdad entre hombres y mu- } \\
\text { jeres }\end{array}$ & $-11,70$ & 136,89 \\
\hline Las infraestructuras & 7,30 & 53,29 \\
\hline \multicolumn{2}{|l|}{ Distancia euclidiana al cuadrado (2011) } & 2059,32 \\
\hline \multicolumn{2}{|l|}{ Distancia euclidiana cuadrada ajustada } & 147,09 \\
\hline
\end{tabular}

Fuente: elaboración propia sobre datos Estudio ES2915 del CIS (2011) 
TABLA 10. 2015: Distancia euclidiana cuadrada entre los perfiles del PP y del PSOE

\begin{tabular}{|l|r|r|}
\hline & $\begin{array}{c}\text { Distan- } \\
\text { cia }\end{array}$ & $\begin{array}{c}\text { Distancia eucli- } \\
\text { diana } \\
\text { al cuadrado }\end{array}$ \\
\hline El empleo & 3,30 & 10,89 \\
\hline La educación & $-1,50$ & 2,25 \\
\hline La sanidad & $-2,20$ & 4,84 \\
\hline La economía & 7,60 & 57,76 \\
\hline La seguridad ciudadana & 5,40 & 29,16 \\
\hline La inmigración & 1,50 & 2,25 \\
\hline El Estado de las autonomías & 2,70 & 7,29 \\
\hline El medio ambiente & 1,20 & 1,44 \\
\hline La Unión Europea & 6,40 & 40,96 \\
\hline La política social & $-3,60$ & 12,96 \\
\hline La vivienda & $-0,90$ & 0,81 \\
\hline La política exterior & 5,90 & 34,81 \\
\hline La igualdad entre hombres y mu- & $-3,10$ & 16,39 \\
\hline jeres & 3,80 & 229,47 \\
\hline Las infraestructuras & & \\
\hline Distancia euclidiana al cuadrado (2015) & & \\
\hline Distancia euclidiana cuadrada ajustada & & \\
\hline
\end{tabular}

Fuente: elaboración propia sobre datos Estudio ES3117 del CIS (2015)

Tal y como se observa en la tabla 11, que resumen los datos anteriores, en la preelectoral de 2015 los dos partidos (Partido Popular y Partido Socialista Obrero Español) estaban muy próximos, en lo que se refleja en la opinión pública, respecto a su eficacia con respecto a todos los temas. La indiferenciación de sus perfiles se aprecia en una "diferencia ajustada" entre ellos de 16,39. Considerando a efectos de interpretación normalizada el significado de lo anterior, y tomando como referencia el rango teórico (posible) que oscila entre 0 (indiferenciación en todos los temas) y 1 (diferenciación total en todos los temas), se observa un coeficiente de 0,001. Más aun, desde una perspectiva ajustada al rango que realmente se ha alcanzado (máximo en 1996) según la mención de los dos partidos en la opinión pública, y nuevamente en el rango de 0 a 1, su coefi- 
ciente de distancia empírico es de 0,004. En ambos casos, la distancia entre las imágenes de partido en lo referido a los temas políticos considerados es mínima.

En 2015 (recordemos la modificación de fraseo que no los menciona explícitamente) sus perfiles sumados solamente son mencionados, como promedio, por el 33,3\% de la muestra (un porcentaje bastante reducido considerando la trayectoria de partidos mayoritarios dentro del sistema de partidos en España). En concreto, un 17,6\% atribuye competencia al Partido Popular, por un 15,7\% al Partido Socialista Obrero Español. Esta situación es claramente descriptiva de la crisis del sistema de partidos que había estado en funcionamiento entre 1989 y 2011, profundizada por la crisis económica internacional iniciada en 2007.

TABLA 11. Dinámica de percepción y distancia entre las imágenes de partido del PP y del PSOE (1996 a 2015)

\begin{tabular}{|l|c|r|r|r|r|r|c|}
\hline & $\begin{array}{c}\text { Distancia } \\
\text { euclidia- } \\
\text { na al } \\
\text { cuadrado }\end{array}$ & $\begin{array}{c}\text { Distan- } \\
\text { cia ajus- } \\
\text { tada }\end{array}$ & $\begin{array}{c}\text { Coeficien- } \\
\text { te } \\
\text { Rango } \\
\text { teórico }\end{array}$ & $\begin{array}{c}\text { Coeficien- } \\
\text { te } \\
\text { Rango } \\
\text { empírico }\end{array}$ & $\begin{array}{c}\text { Prome- } \\
\text { dio }^{5} \text { de } \\
\text { mencio- } \\
\text { nes }\end{array}$ & $\begin{array}{c}\text { Perfil } \\
\text { PP }\end{array}$ & $\begin{array}{c}\text { Perfil } \\
\text { PSOE }\end{array}$ \\
\hline 2015 & 229,47 & 16,39 & 0,001 & 0,004 & $33,35 \%$ & $17,62 \%$ & $15,72 \%$ \\
\hline 2011 & 2059,32 & 147,09 & 0,014 & 0,037 & $55,53 \%$ & $31,33 \%$ & $24,19 \%$ \\
\hline 2008 & 1989,95 & 153,07 & 0,015 & 0,039 & $46,87 \%$ & $17,78 \%$ & $29,08 \%$ \\
\hline 1996 & 2633,04 & 239,36 & 0,023 & 0,061 & $62,23 \%$ & $28,45 \%$ & $33,78 \%$ \\
\hline
\end{tabular}

Fuente: elaboración propia sobre los datos ES2207 ES2382 ES2750 ES2915 ES3117

Considerada la dinámica seguida por las distancias, es apreciable un proceso de convergencia e indiferenciación en la imagen de partido del Partido Popular y del Partido Socialista Obrero Español. Dentro de dicho proceso se observan dos anomalías ya diagnosticadas en otros estudios (Alaminos A. y Alaminos P. 2007). Se trata de la anomalía de las elecciones de 2000 (que resultaron en una mayoría absoluta del Partido Popular) y que coincide con la atenuación del perfil temático del Partido Socialista Obrero español, que se reduce al 14\%, asocia-

\footnotetext{
${ }^{3}$ Coeficiente respecto a máxima diferenciación teórica en sus perfiles (entre 0 indistintos y 1 completamente diferentes)

${ }^{4}$ Coeficiente respecto a máxima diferenciación empírica (1996) en sus perfiles (entre 0 indistintos y 1 completamente diferentes)

${ }^{5}$ Promedio de la suma de temas de la imagen: opinan sobre Partido Popular y Partido Socialista Obrero Español

${ }^{6}$ Promedio de la suma de temas de la imagen del Partido Popular

7 Promedio de la suma de temas de la imagen del Partido Socialista Obrero Español
} 
do a una elevada abstención del votante socialista. La segunda anomalía se aprecia en las elecciones de 2011, en este caso con el Partido Popular como protagonista y una elevación contra tendencia de su perfil de gestión. Esencialmente a partir de los temas de "economía" y "empleo". La elevación del perfil del Partido Popular se produce en un contexto de profunda crisis en la que el gobierno socialista había desarrollado una política de recortes del estado de bienestar, y en un clima donde los discursos políticos del Partido Popular prometían revertir las políticas adoptadas hasta entonces. La elevación de la competencia supuesta al Partido Popular se incrementa asociada, nuevamente, a la tensión abstencionista de los electorados socialistas.

Localizadas las dos anomalías, asociadas a momentos significativos en términos de clima socioeconómico y político, y caracterizadas por descensos notables en el apoyo electoral del Partido Socialista Obrero Español (elevada abstención electoral selectiva), es factible apreciar claramente la tendencia decreciente según la que los dos partidos aproximan su imagen en términos de ineficacia. Así, el promedio acumulado de visibilidad de los dos partidos pasa de $62,2 \%$ en el 1996, al 33\% en 2015. Por partidos, en términos analíticos, se observa (controlando las anomalías) como para el Partido Socialista Obrero Español es de un $33,7 \%$ en 1996, el 29\% en 2008, un $24 \%$ en 2011 y el 15,7\% para el 2015. El Partido Popular la tendencia es asimismo descendente con el $28 \%$ en 1996, el 22,9\% en el 2000, un 17,7\% en 2008 y el 17,6\% en el 2015. En los dos se aprecia un paulatino descenso de su relevancia distintiva para la gestión de las temáticas consideradas. Esa convergencia se refleja claramente en la medición de la distancia entre sus imágenes de partido.

En 1996 la distancia ajustada entre los dos partidos era de 239,3, reduciéndose en el 2008 a 153, descendiendo hasta 147 en el 2011 y finalmente, con la entrada de nuevos partidos políticos, hasta un 16,3 en el 2015. En el 2000 se anticipa una fuerte aproximación de imágenes, previa a la mayoría absoluta del Partido Popular. Se observa como desde 1996 la imagen de los dos partidos en la opinión pública se ha hecho cada vez más indistinta, aproximando su capacidad para la solución de los diferentes temas. En el caso de las elecciones de 2015, la proximidad entre ellos es máxima, correspondiendo con la crisis política y social que se vivía en la sociedad española.

En todo caso, tras la evidencia de una cierta especialización temática entre los dos partidos en la encuesta de 1996, y que probablemente sea generalizable al periodo de los gobiernos socialistas anteriores, la distancia entre la imagen de los dos partidos en la opinión pública ha sido bastante reducida, especialmente desde el año 2000. Considerando el coeficiente según rango teórico, es decir la máxima diferenciación que se podría producir de asignar toda la muestra una temática a alguno de los dos partidos, la distancia entre el Partido Popular y el Partido Socialista Obrero Español es bastante reducida. Con un límite superior de uno e inferior de cero, la distancia entre los dos partidos era de 0,02 en 1996, 
del 0,01 entre 2000 y 2011, y de un 0,001 en 2015. Una imagen semejante se aprecia si se observa el coeficiente empleando para la estimación de máximos el porcentaje que ha reconocido a los dos partidos como los más capacitados en dichos temas. La distancia máxima es de 0,06 en 1996, 0,027 en 2000, 0,039 en 2008 y 0,037 en 2011. Todas las distancias son cada vez más reducidas, dentro de la proximidad ya existente entre ellas. Nuevamente, el año 2015 refleja una crisis de las imágenes del bipartidismo, con un coeficiente de 0,004. El coeficiente muestra como las imágenes de partido del Partido Popular y del Partido Socialista Obrero Español en 2015 están realmente muy próximos en la opinión pública española.

Considerando los datos empíricos, puede afirmarse como la crisis del bipartidismo en España se produce en el contexto de una tendencia progresiva de indiferenciación de las imágenes de partido entre el Partido Popular y el Partido Socialista Obrero Español en la opinión pública a nivel nacional.

\section{CONCLUSIONES Y DEBATE}

Los datos considerados muestran una elevada proximidad en las imágenes de partido del Partido Popular y del Partido Socialista Obrero Español a partir del 2000. Una proximidad de imágenes de partido que indican una tendencia según la cual se incrementa la indistinción entre sus ofertas políticas. Dicho en otro modo, las posiciones temáticas del Partido Popular y del Partido Socialista Obrero Español son percibidas como muy similares en la opinión pública española, en un proceso que reduce los perfiles distintivos de los dos partidos. En ello influyen tanto las experiencias de gobierno, con políticas condicionadas por un mismo paradigma económico o decididas en el espacio europeo.

Entre las observaciones cabe afirmar como, si bien la distancia global en 1996 no era especialmente elevada, esto puede responder a una diferenciación más importante en el periodo anterior (Alaminos y Penalva, 2010). En la encuesta de 1996 no existía experiencia de gobierno del Partido Popular, algo diferente para la encuesta de 2000, en la que ese conocimiento ya existía. En cierto modo, cabe plantear la hipótesis de una imagen de partido menos diferenciada tras la experiencia de gobierno de los dos partidos, y mayor cuando no existía dicha experiencia. En ese sentido, los datos considerados se refieren a un periodo en el que las expectativas o prejuicios sobre la actuación política del Partido Popular en varios temas (normativa sobre la interrupción del embarazo, por ejemplo) ya se han atenuado o disipado.

Asimismo, otra observación se refiere a que los temas propuestos en las encuestas de opinión pública no contemplaran aquellos que pudieran ser, en ese momento, propios o específicos de cada uno de los partidos. Sin embargo, sí es 
evidente que los temas que se mantienen desde el inicio de la serie y que definían las distancias entre los dos partidos en 1996, pierden peso en los años sucesivos para diferenciar entre ellos. De hecho, dado que los cuestionarios son diseñados con uno de los dos partidos en el gobierno, se aprecia la introducción de nuevos temas que antes no aparecían y que son significativos para dicho partido. Un caso evidente es en 2011 con la introducción de la "igualdad entre hombres y mujeres" de forma expresa. Con el gobierno socialista aún en ejercicio, se consideraba uno de los temas estrella y de referencia de dicho partido. El tema se mantiene con el mismo fraseo en la encuesta preelectoral de 2015, ya con el gobierno popular. En ese sentido, a los temas tradicionales se incorporan temas nuevos que se consideran relevantes en ese momento ("inmigración" en el año 2000), al igual que desaparecen otros como el "terrorismo" o la única mención a "combatir la corrupción" es de 1996.

La pérdida de diferenciación en lo que se refiere a la mayoría de los temas políticos significativos implica una evidente dificultad en las campañas electorales, dado que la posibilidad de ofrecerse como alternativa es más difícil. De hecho, disuelve gran parte de las líneas de conflicto ideológico entre los dos partidos dado que, a partir de la experiencia de gobierno de ambos, limita a temas muy puntuales y coyunturales el debate entre ellos. Es el caso, por ejemplo, de temas como la corrupción, que fue herramienta empleada por el Partido popular contra el Partido Socialista hasta el año 2000 y viceversa, empleado por el PSOE contra el Partido Popular posteriormente. La igualdad de género se convirtió por un tiempo en una arista definitoria de la imagen de partido del PSOE, si bien dicha diferenciación se diluyó con el impacto de la crisis económica. En la actualidad, encontrar nichos temáticos diferenciadores es un auténtico problema entre los partidos con experiencia de gobierno en la derecha y en la izquierda, especialmente en lo relacionado con la economía.

Esa reducción de los espacios de competencia influye de forma sustantiva en las formas de campaña y en sus contenidos. Así, la teoría espacial del voto considera que la oferta electoral de un partido se optimiza mediante una función que determina la combinación de temas políticos en los que dicho partido presenta una posición dominante. En una situación electoral donde la función de optimización ofrece las mismas políticas (temas) y la capacidad de diferenciarse en lo que se ofrece para cada una de ellas es mínima, reduce el espacio temático de la contienda electoral, limitando las campañas a cuestiones de confianza en líderes, titulares llamativos, descalificaciones y recursos a la trayectoria y errores de los contendientes en el pasado. En dichas condiciones de contienda electoral, el clima social y político, es decir, la coyuntura, son esenciales (Bouza, 2010), y es en dicho espacio, donde los medios y la "agenda setting", ocupan un papel especialmente central, que trasciende la ya de por sí importante mediatización de la política. 


\section{BIBLIOGRAFÍA}

Alaminos, A. y Alaminos Fernández, P. Las dinámicas del voto retrospectivo en España (1996-2017). Tendencias Sociales. Revista de Sociología. Aceptada pendiente de publicación. En prensa.

Alaminos, A. y Alaminos-Fernández, P. (2017) “La potencia estadística prospectiva del voto retrospectivo en España (1996 a 2015)". OBETS. Revista de Ciencias Sociales, 12 (Extra 1): Partido Popular-Partido Popular. 249-278.

Alaminos, A. et al. (2015) Análisis multivariante para las Ciencias Sociales I. Índices de distancia, conglomerados y análisis factorial. Cuenca: Pydlos

Alaminos, A. (2015) "Forecasting elections with high volatility". Italian Journal of Applied Statistics. 25 (2), 165-184.

Alaminos, A. (2012) "Missing mixed mode: elemental structures". OBETS: Revista de Ciencias Sociales. Número 7. Páginas 327-333

Alaminos, A. y Penalva, C. (2010). “Los medios de comunicación y el cambio político en España (1991-2000)”. Sistema. Revista de Ciencias Sociales, (217) $19-40$

Alaminos, A. y Castejón, J.L. (2006) Elaboración, análisis e interpretación de encuestas, cuestionarios de escalas de opinión. Alicante: Marfil.

Alaminos, A. (1996) "Las predicciones electorales de las elecciones generales de 1996 en España". En VVAA. Elecciones Generales 1996 y medios de comunicación en la región de Murcia. Murcia: Fundación Instituto de la Comunicación de Murcia

Alaminos, A. (1994). "Predicciones electorales en España" en Alaminos et al., Future Days. Alicante: Fundación Cultural CAM.

Alaminos, A. (1991). Teoría y práctica de la encuesta. Madrid: CEDEAL

Alaminos, A., Francés, F., Penalva, C., Santacreu, O. (2015). Análisis multivariante para las Ciencias Sociales I. Índices de distancia, conglomerados y análisis factorial. Cuenca (Ecuador): PYDLOS

Almond, G. y Verba, S. (1965) The Civic Culture. Boston: Little, Brown

Alt, J.E. (1984). "Dealignment and the Dynamics of Partisanship in Britain." En Dalton, Russel et al. Electoral Change in Advanced Industrial Societies: Realignment or Dealignment? Princeton: Princeton University Press.

Bouza, F. (2010): "Las Agendas de la ciudadanía durante la crisis económica", Mediterráneo Económico, 18, La crisis de 2008. De la economía a la política y más allá, pp. 233-247.

Bouza, F. (2007) “La inseguridad ciudadana en las agendas pública y personal de los españoles (2000-2004)". Política y Sociedad, 44, 3, pp.183-194.

Bouza, F. (2004): “The impact area of political communication: Citizenship faced with public discourse". International Review of Sociology, 14, 245-259.

Bouza, F. (1998). Comunicación Política: Encuestas, Agendas y Procesos Cognitivos Electorales. Praxis Sociológica. no 3, pp. 49-58 
Brewer, M.D. (2009), Party Images in the American Electorate. New York: Routledge

Chavero P., González J.J., Bouza F., Castromil A. y Rodríguez R. (2013): “La mediatización de la agenda política: la discusión del pacto social como conflicto de agendas, 2009-2011", Revista Latina de Comunicación Social. Pag. 639 - 655

Easton, D. (1975) "A Re-Assessment of the Concept of Popular Support" British Journal of Political Science, 5. Pág: 435-57

Francés F. et al. (2014) El proceso de medición de la realidad social: La investigación a través de encuestas. Cuenca (Ec): PYDLOS.

Franklin, Ch.H. 1984. "Issue Preferences, Socialization, and the Evolution of Party Identification." American Journal of Political Science 28: 459-78.

González, J.J. y Novo, A. (2011): “The Role of the Media Agenda in a Context of Political Polarization", Comunicación y Sociedad. vol. XXIV, n. 2, 2011, pp.78-131.

González JJ. y Bouza F. (2009) Las razones del voto en la España democrática, 19772008. Madrid: Los libros de la Catarata

Jennings, M.K. y Niemi, R.G. (1974). The Political Character of Adolescence: The Influence of Families and Schools. Princeton: Princeton University Press.

Parsons, T., Shils, E. (1951). Toward a general theory of action. Cambridge: Harvard University Press.

Piqueras, J.A. et al. (2011) El secuestro de la democracia: corrupción y dominación política en la España actual. Madrid: Akal.

Sanders, A. (1988) The Meaning of Party Images. The Western Political Quarterly Vol. 41, No. 3, Pp. 583-599

Tezanos, J.F. y Luena, C. (2017). Partidos políticos, democracia y cambio social. Madrid: Biblioteca Nueva.

Trilling (1976) Party image and electoral behavior. New York: John Wiley and Sons

Wattenberg, M.P. (2000) “The decline of party mobilization" en Dalton, Russel y Wattenberg, M.P. (editors) Parties Without Partisans: Political Change in Advanced Industrial Democracies. Oxford: Oxford University Press.

Wattenberg, M.P. (1986) The decline of American Political Parties, 1952-1984. Cambridge, Mass.: Harvard University Press

ANTONIO F. ALAMINOS CHICA. Catedrático de Sociología en la Universidad de Alicante.

RECIBIDO: 01/04/2017

ACEPTADO: 04/05/2017 